Scientific Visualization, 2020, volume 12, number 1, pages 48 - 6o, DOI: 10.26583/sv.12.1.04

\title{
Visualization of CAE-solutions of partial problems of ice navigation. Icebreaker sitting and propulsion ability
}

\author{
V.A. Lobanov ${ }^{1}$ \\ Federal State-Financed Educational Institution of Higher Education «Volga State Univer- \\ sity of Water Transport» (FSFEI HE VSUWT), Russia \\ 1 ORCID: 0000-0002-0931-7317, lobbas@mail.ru
}

\begin{abstract}
The article is devoted to ice navigation with particular emphases on the operation of icebreaking that ensures efficiency and safety of ice transport services. The ice transport services are distinguished by a wide range of necessary operations, actions, maneuvers, the modes and dynamic working methods. It reserves a burning relevant a problem of assessment of ice performances in special operating conditions. In this work CAE modeling of the movement in continuous ices, ice cakes and small ice cakes of the multishaft shallow-draft icebreaker ship of the project 1191 is considered. The different combinations of its draft, a list and a trim are investigated. Qualitative features of influence based on the nature of interaction of the vessel with the ice environment are described. Comparative analysis of experimental data of ice loads on the hull and a propulsion, as well as the steering complex are made. Quantitative assessments of ship based on its total ice resistance are given.
\end{abstract}

Keywords: icebreaker, propulsion and steering complex, ice condition, ice channel, CAE-system, finite element modeling.

\section{Introduction}

This work continues a series of the publications devoted to use of visualization tools of modern CAE-systems for estimating of the ice performance of vessels in special operating conditions [4].

The CAE-system (Computer Aided Engineering) is the computer technology modeling and visualizing space time development of the studied process. At present similar technologies find the application in different areas of knowledge: mechanics, hydra, gas and thermodynamics, construction, processing of materials, medicine, nuclear physics, hydrometeorology, micro and macrocosm, etc. A basis of the CAE-system is the numerical solver of systems of the differential equations describing behavior previously sampled (it is normal in a finite element formulation) areas of space (environment, bodies). At the same time it should be noted that in addition to the fulfilled numerical methods the convergence of the decision is obtained with use of the special «artificial» programs, algorithms and procedures.

All set of the sea and river ice technology problems belongs to the extensive class of mechanics of deformable environments. The basic scientific novelty of CAE technologies is consideration of problems of mechanics via modeling of objects interactions unlike modeling of loadings that is traditional semi-empirical approach considered by the majority of numerical methods. In problems of assessment and forecasting of ice performances of the fleet the approach allows to pass to implementation of nonautonomous models of interaction of the ship hull and its propulsion and steering complex with the water ice environment. Unlike the classical autonomous solutions [5-8] considering influence of only quantitatively static isotropic environment on the vessel, CAE models describe interference of the vessel and environment taking into account stochasticity of this process in space and time. Also important advantage 
of the CAE-analysis it is necessary to acknowledge the possibility of separation of hydrodynamic and ice loads that it is unavailable to a model experiment and natural tests.

Essentially significant stage of CAE technologies is the postprocessing implementing processing of results of modeling by means of scientific visualization. Post-processor tools in problems of a sea and river ice technology are three-dimensional graphics with a rich set of options for the analysis of model (scaling, detailing, tools for measurements, gradient fields of parameters, levels, isolines, traces, sections, cuts, vectors, transparency, etc.), animation and also the graphic processor creating different nodal and element space time functions at a possibility of their mathematical analysis [12].

A sufficient number of analytical, semi-empirical and numerical techniques for the forcasting of ice resistance, icebreaking capability and propulsion ability of vessels so far have been proposed [1-7]. They give the acceptable level of adequacy in the analysis of ice problems of operational character. However the applicability of such techniques is fair only for «trim on an even keel» vessels at their design draft. At the same time, the trim and a list as factors of case ice resistance and loadings on a propulsion and steering complex are not considered in principle. It is caused by the fact that actually transport ship having an ice class should be loaded on the level of design draft (its strongest strip of «an ice belt»). Therefore for ice category cargo fleet the removal of sitting of the vessel from the list of the arguments influencing ice propulsion ability is admissible.

Operation of icebreaking means in comparison with cargo ships is distinguished by much wider range of the modes and dynamic working methods. At the same time natural observations of work of the fleet in ices $[8,9]$ show relevance of periodic modes of the movement of ice breakers with the changed sitting that saves relevant a problem of the forecast of ice maneuverability and propulsion ability for such conditions of their operation.

Scientific and technical research of the author is connected with estimates of ice performances of vessels for inland and coastal navigation. Those types of vessels can be classified by ice criteria of belonging to not Arctic categories. The criteria's of acceptable safety and efficiency of ice operations for such fleet can only be satisfied in the conditions of small ice cakes and brash ice. The formation of such ice environment for the fleet with low (not Arctic) ice categories is provided with icebreaking means with multishaft propulsions and steering complexes. This means the vessels for internal waterways and coastal sea , that is the case of the ice breaker of the project of 1191 types «Captain Evdokimov».

After preliminary study of ice potential of this vessel [8], the author did not find any information on quantitative impact assessments of his sitting on ice propulsion ability. The needs for the solution of partial problems of icebreaking works are interfered by restrictions in implementation of natural tests of ice breakers. As an alternative to model experiment in ice pools for these purposes can not always be recommended due to a number of its shortcomings those are mainly the imperfection of model ice (and, especially, by consideration of interaction of a propulsion and steering complex with ice). The impossibility of separation of ice and hydrodynamic influence on the ship hull and its propulsion and steering complex, identifications of the making ice loads (on the hull, propellers, rudders) is also essential limitation for obtaining representative data in both above-mentioned cases.

The experience of the author shows that in the absence of solid natural or empirical data these decisions are admissible to be received with use of CAE technologies [4, 10, 11, 12]. Below it is illustrated with results of the next series of CAE ice tests (about application of a LSDYNA [12] package) the shallow-draft icebreaker at different options of its sitting.

\section{Nature of ice interaction}

The qualitative analysis of CAE simulation of work of the icebreaker in ice cakes showed that in a real «working» (safe) interval of retrimming, a list and the draft of the vessel you should not expect notable interalternative features of ice loads on the interacting structural elements (the hull, thrusters, rudders). It well explains fig. 1. 

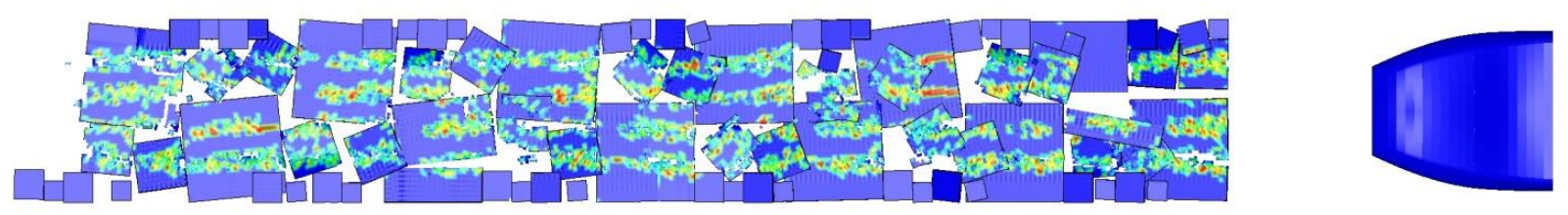

a

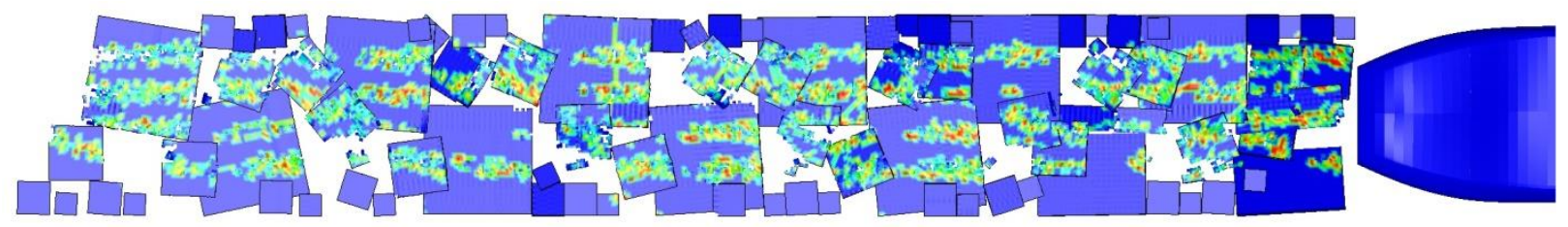

b

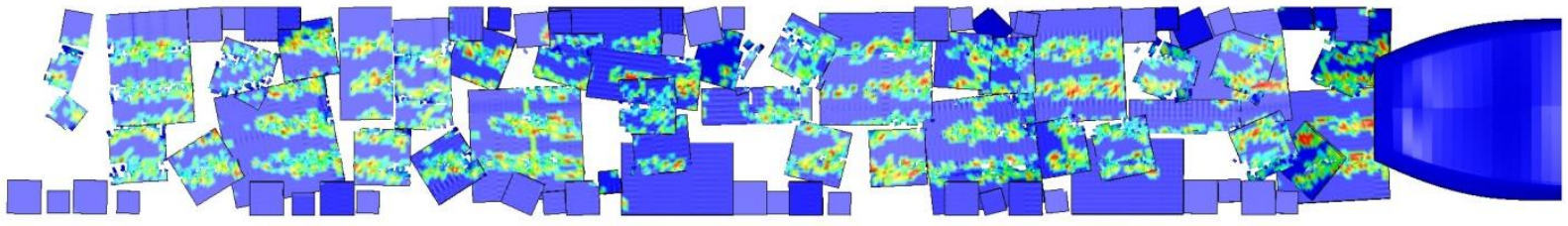

C

EVEN KEEL T 2_5

Time $=\quad 0$

max ipt. value

$\min =0$, at elem\# 2001

$\max =0$, at elem\# 2001

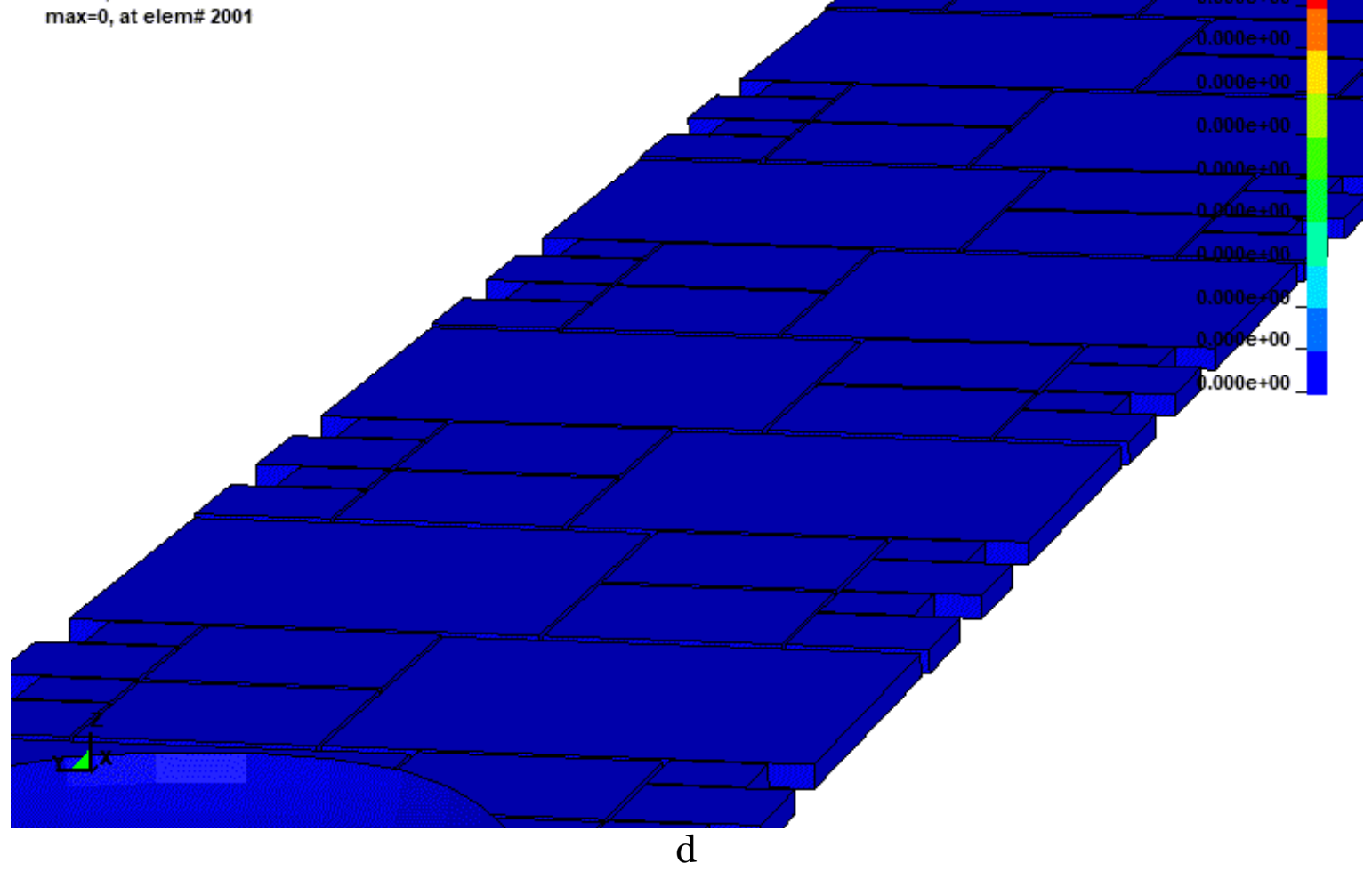




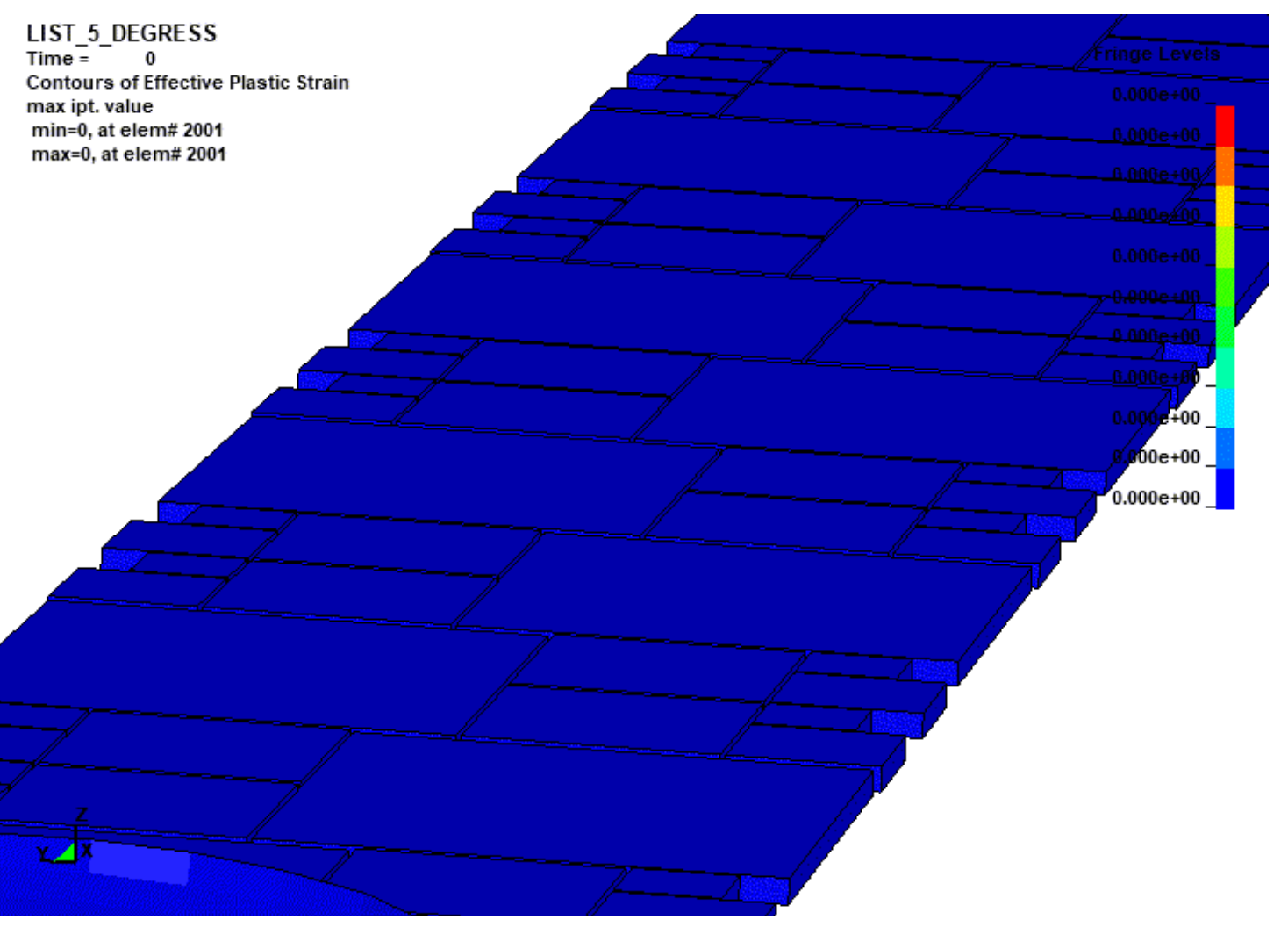

e

Fig. 1. A condition of «model» channels in ice cakes at different options of an icebreaker sitting

(a, d - sitting on «even keel» at a design draft of 2,5 m; b, e - a list of 5 degrees; $\mathrm{c}-\mathrm{a}$ list of 5 degrees, a trim by the stern 2 degrees)

By the form «model» ice channels (the nature of distribution of ices, their degree of fragmentation and concentration, fig. 1) the user can judge on a loosely correlation of ship sitting with a condition of the ice route after passing of the icebreaker. This assumption qualitatively (Fig. $1 \mathrm{~d}, 1 \mathrm{e}$ ) and quantitatively (Fig. 2) is also confirmed by the analysis of modes of vibration of propellers of the vessel.

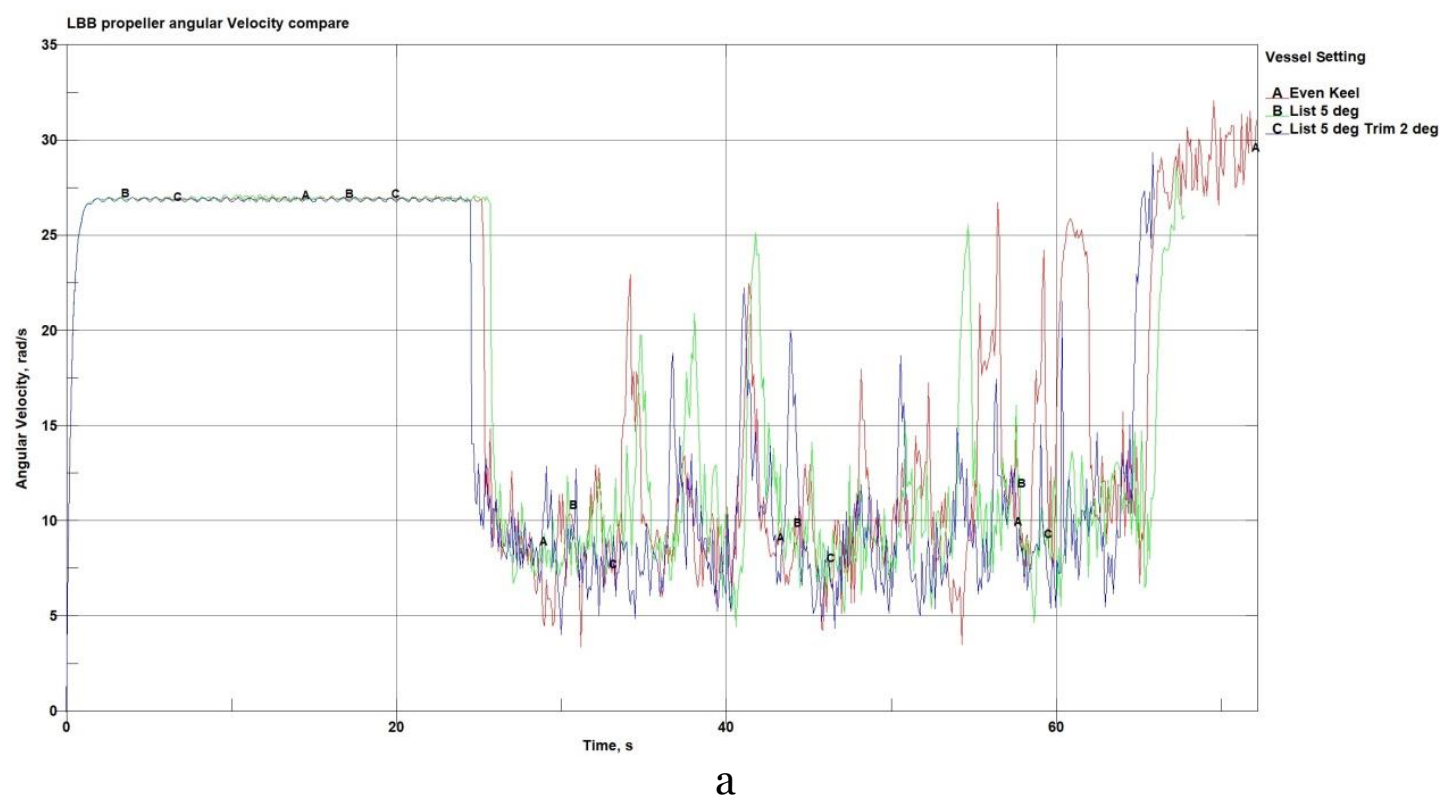



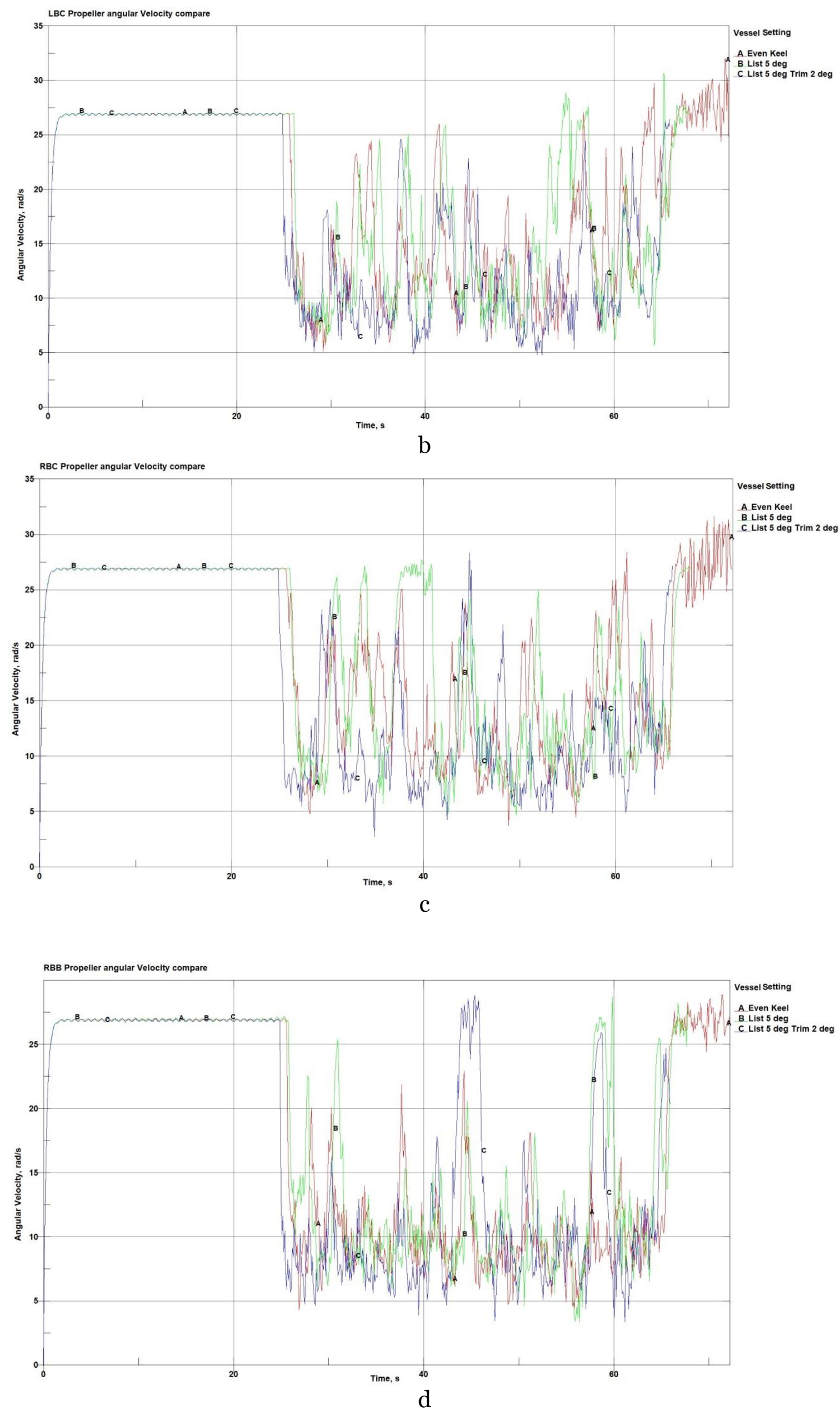
Fig. 2. The time nature of rotating speed of thrusters at different options of an icebreaker sitting

( $\mathrm{a}$ - the outboard port propeller; $\mathrm{b}$ - the inboard port propeller;

$\mathrm{c}$ - the inboard starboard propeller; $\mathrm{d}$ - the outboard starboard propeller)

In fig. 2 mode of vibration of propellers for three options of overcoming an ice crossing point by the icebreaker from ice cakes $0,5 \mathrm{~m}$ thick and concentration of 9-10 balls are illustrated. At the same time each option is characterized by individual ship sitting.

The analysis of oscillograms of fig. 2 shows that the time nature of rotating speed of any propeller (curves A - ship sitting on «even keel» at a molded draft of 2,5 m; curves B - a vessel list by 5 degrees; curves $\mathrm{C}-\mathrm{a}$ list of the vessel of 5 degrees, a trim by the stern 2 degrees) saves characteristic instability in each of three mentioned icebreaker sitting options. Also it is necessary to note that in all rated options of CAE testing predicts almost continuous contact of all propulsion and steering complex of the vessel with the ice cover which is «flowing round» the hull.

Qualitative interalternative features of the process of breaking of a compact ice are more obvious in comparison with ice cakes (Fig. 3). However, anunambiguous identification of the created ice channels on the basis of an icebreaker sitting is not always available even to the experienced ice captain or the hydrologist (Fig. 4a, 4b).

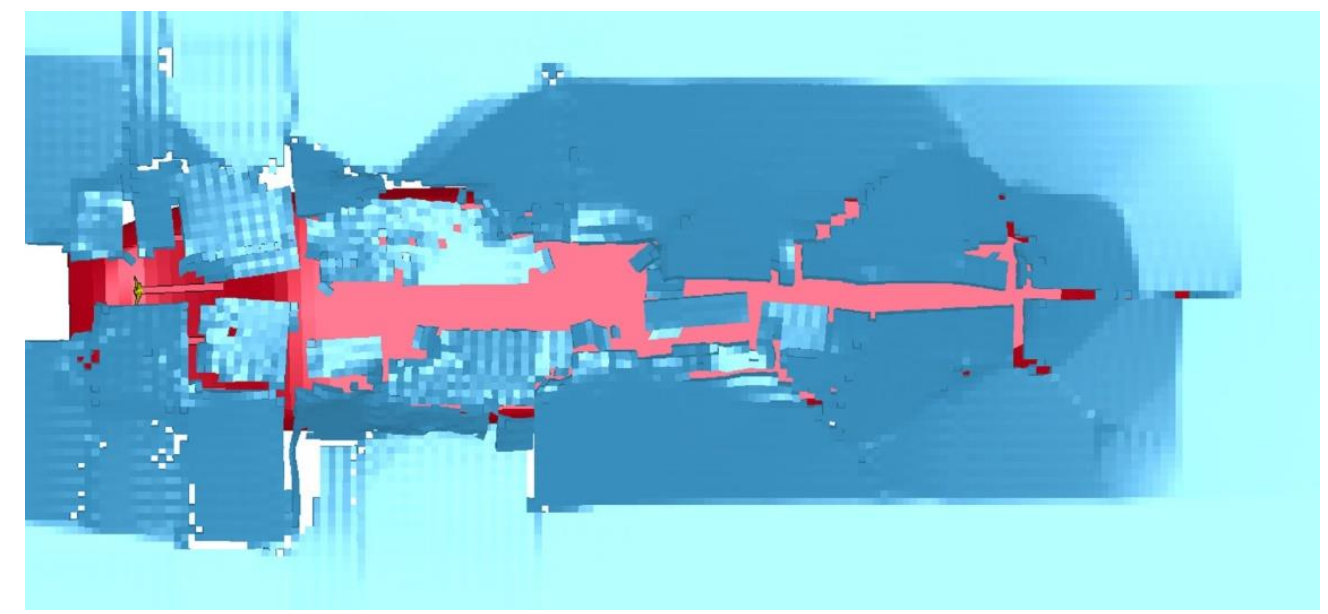

a

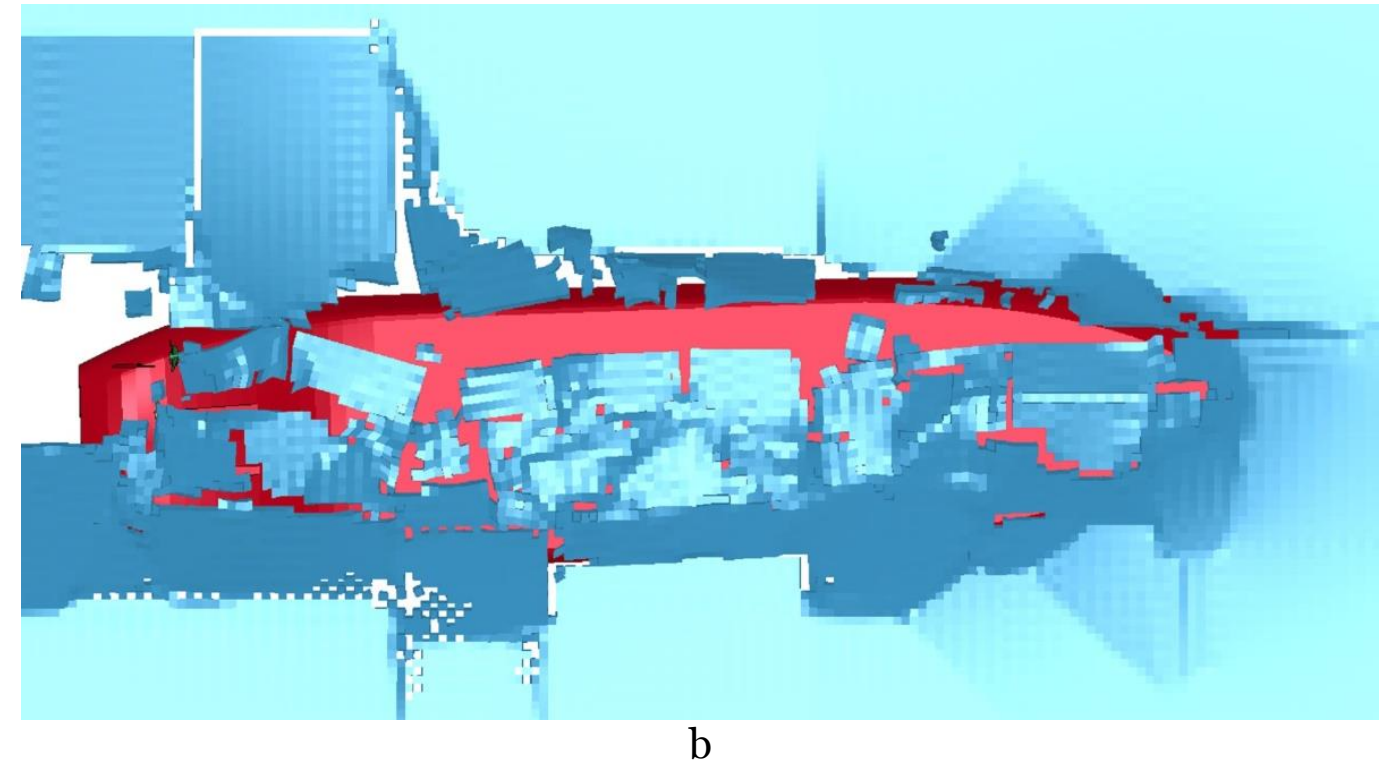

Fig. 3. The nature of breaking of a compact ice at different options of an icebreaker sitting (bottom view)

( $\mathrm{a}$ - sitting on «even keel» at a design draft of $2,5 \mathrm{~m}$; b - a list of 5 degrees) 


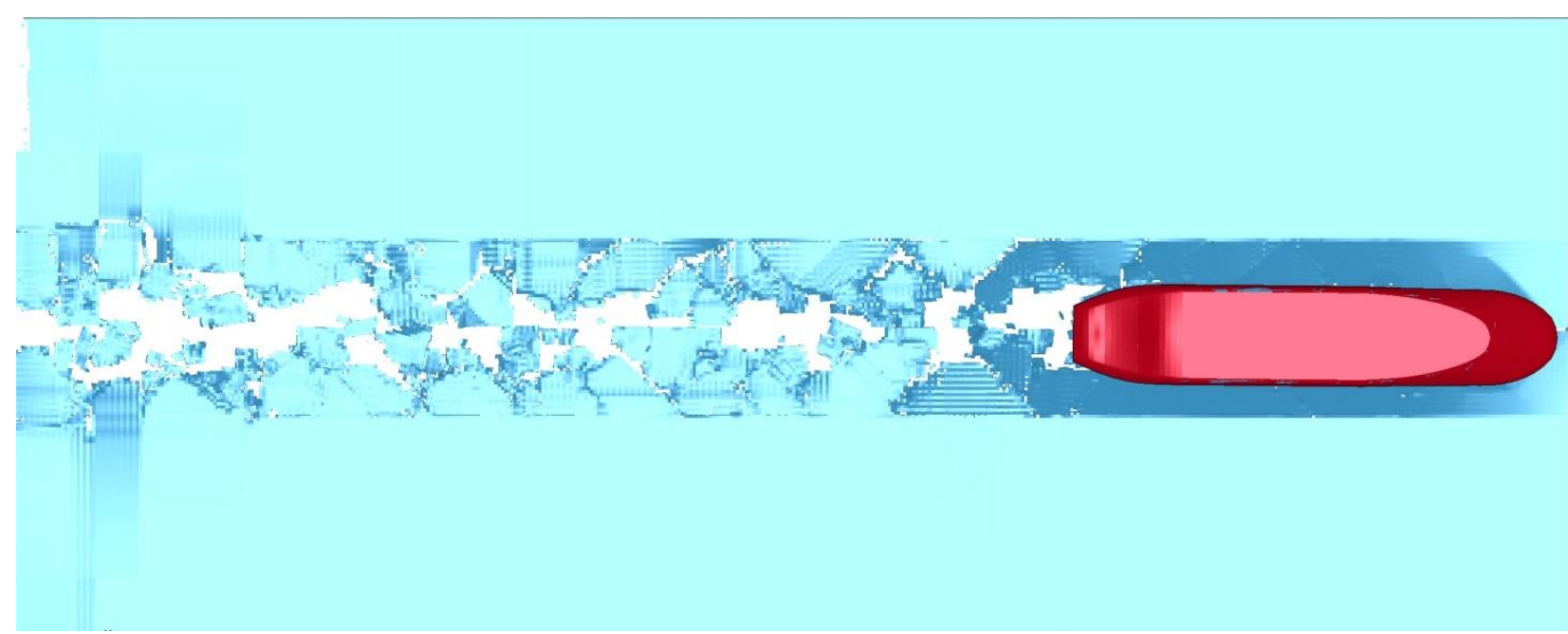

a
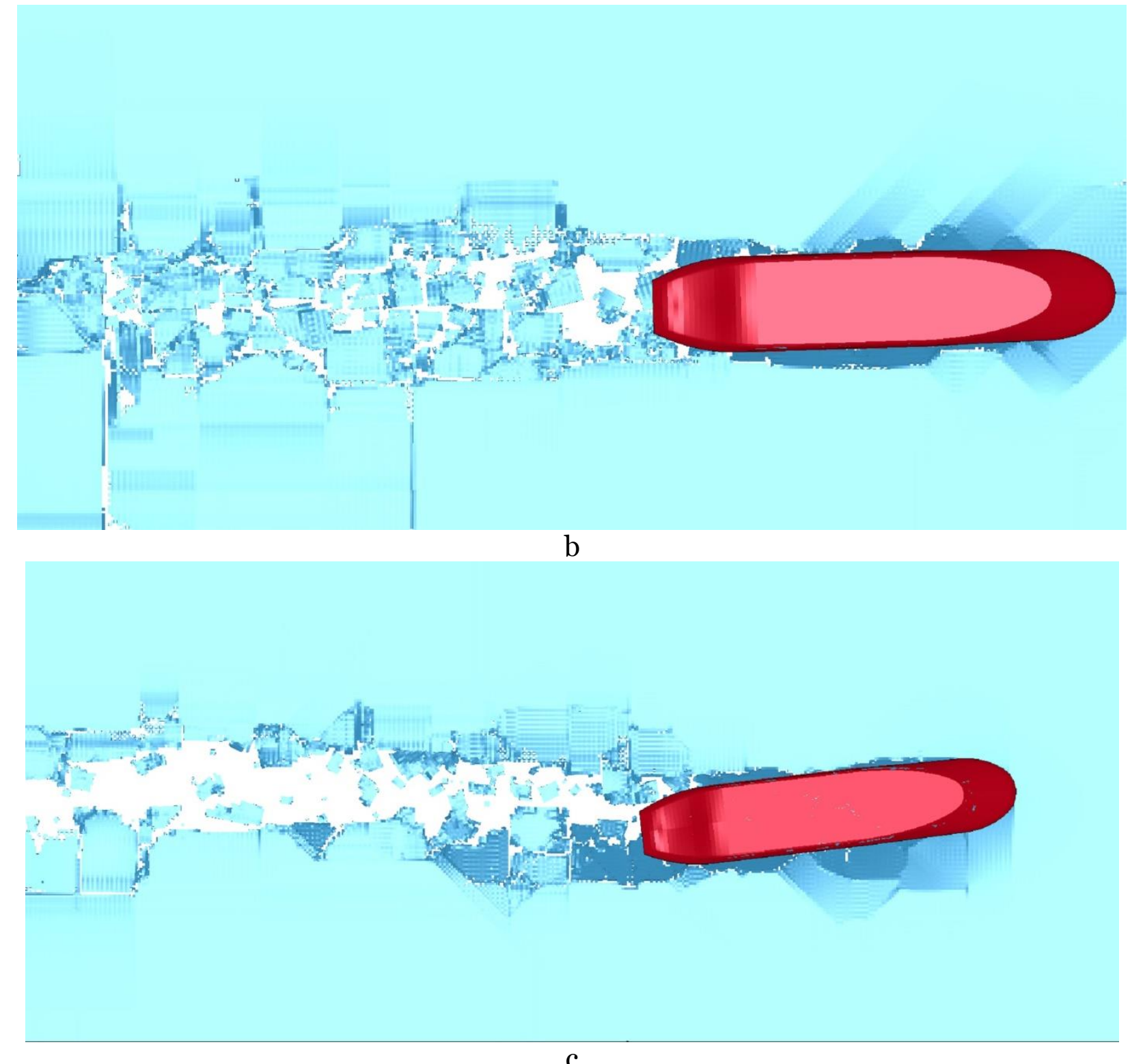

Fig. 4. A qualitative condition of «model» channels in compact ices at different options of an icebreaker sitting

(a - sitting on «even keel» at a design draft of $2,5 \mathrm{~m}$;

$\mathrm{b}-\mathrm{a}$ trim by the stern 2 degrees; $\mathrm{c}-\mathrm{a}$ list of 5 degrees) 
It should be noted that existence of a list causes stochastic fluctuations of lateral ice hull loads. The last worsens route stability of the icebreaker [10] at the movement in a continuous ice cover that can obviously be reflected in a form and a condition of the ice channel (Fig. 4c). At the same time already at the qualitative level reduction of speed of the course in relation to sitting option «on an even keel» is noted (Fig. 5, curves B and A respectively).

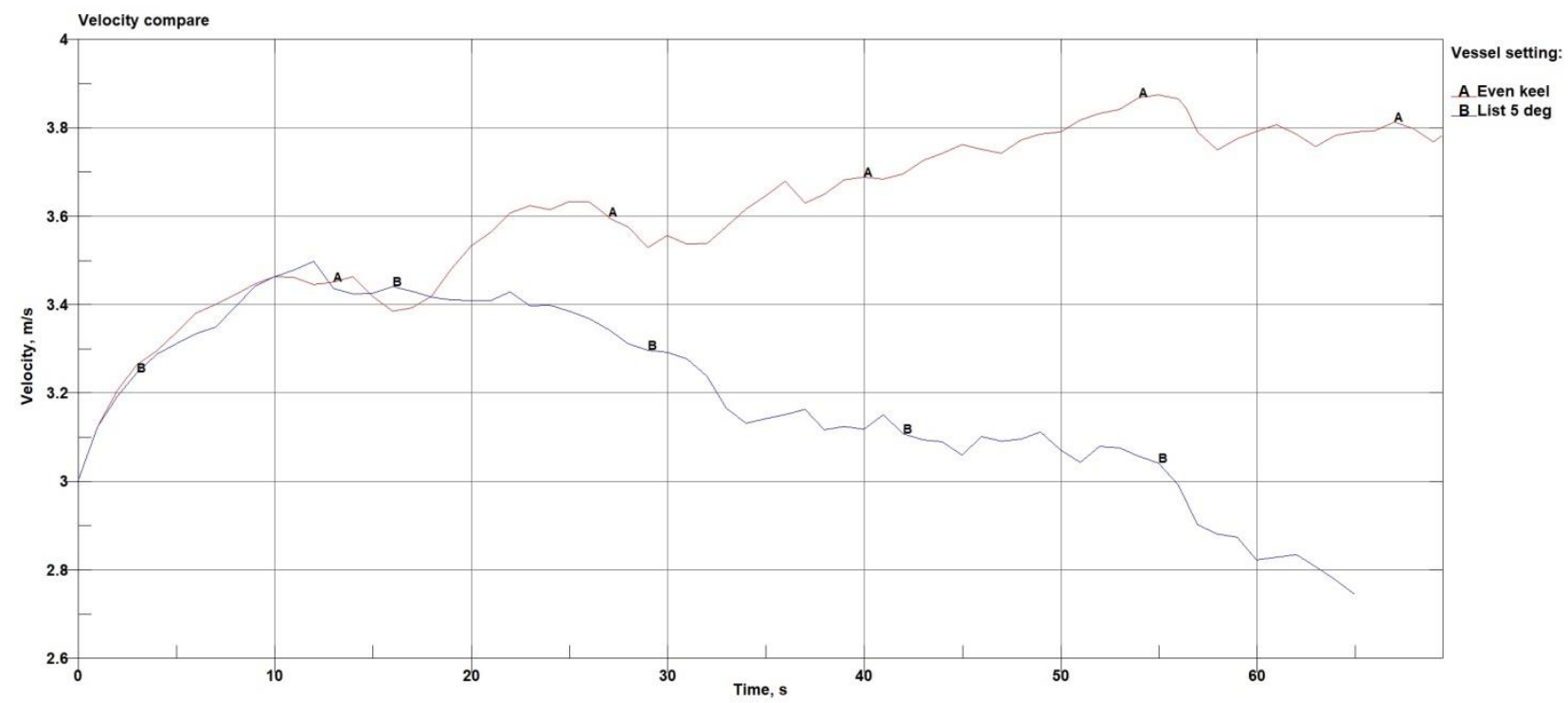

Fig. 5. Time character of motion speed of the icebreaker in compact ices at different options of its sitting

The features in the nature of the movement and dynamics of the different icebreaker sittings in compact ices illustrated in fig. 4 and 5 . Those features with high degree of probability are accompanied by interalternative differences in ice loads on a hull and its propulsion and steering complex.

\section{Ice resistance}

The quantitative results of CAE estimates of the resulting ice resistance for several options of the sitting of the icebreaker in ice cakes are shown in fig. 6 .

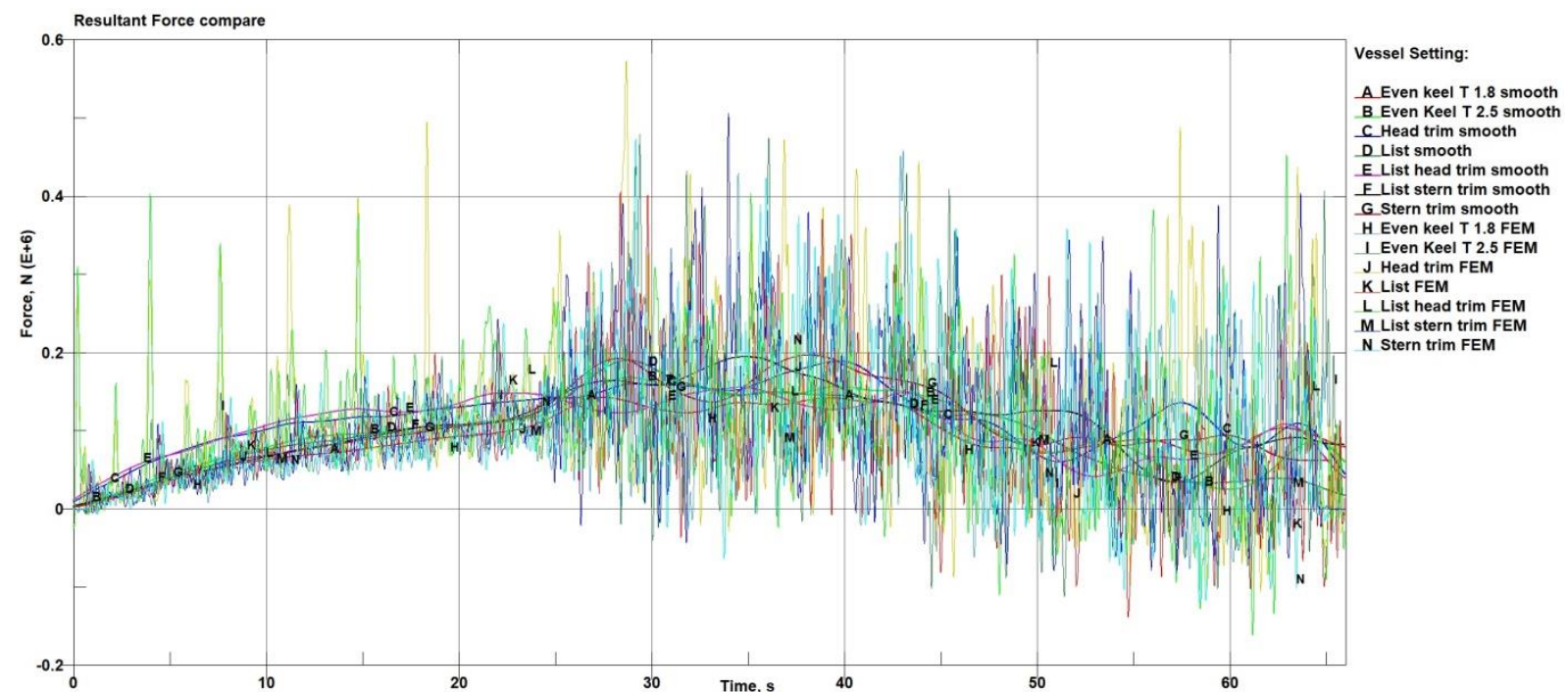

Fig. 6. Comparison of ice resistance of the icebreaker in ice cakes at different options of its sitting

(A - sitting on «even keel» at the draft of $1,8 \mathrm{~m}$, smoothed values; B - sitting on «even keel» at the draft of $2,5 \mathrm{~m}$, smoothed values; $\mathrm{C}-\mathrm{a}$ trim by the bow 2 degrees, smoothed values; $\mathrm{D}-$ 
list of 5 degrees, smoothed values; $\mathrm{E}$ - trim by the bow 2 degrees and list of 5 degrees, smoothed values; $\mathrm{F}$ - trim by the stern 2 degrees and list of 5 degrees, smoothed values; $\mathrm{G}-$ trim by the stern of 5 degrees, smoothed values;

$\mathrm{H}-\mathrm{N}$ - according to curve $\mathrm{A}-\mathrm{G}$ results of CAE modeling)

(Fig. 6, curve A-G) can be inferred by the analysis of smoothed curves that the level of total ice resistance of the vessel is individual in each option of its sitting. At the same time onetime differences in ice loads can accept significant sizes (Fig. 6, it most obviously later $\sim 25 \mathrm{~s}$ when the vessel completely «goes deep» into the ice field and, except the hull, begins active contact with ices of thrusters and rudders of the icebreaker). However in dynamics these distinctions have the sign-variable character that is a testimonial of the fact that the correlation of an icebreaker sitting with the level of its total ice resistance is not significant.

Separation of ice resistance on constructive components (the hull, rudders, thrusters) stands on hind legs of ice loads, similar fig. 6 (Fig. 7, designations of curves correspond to fig. 6).
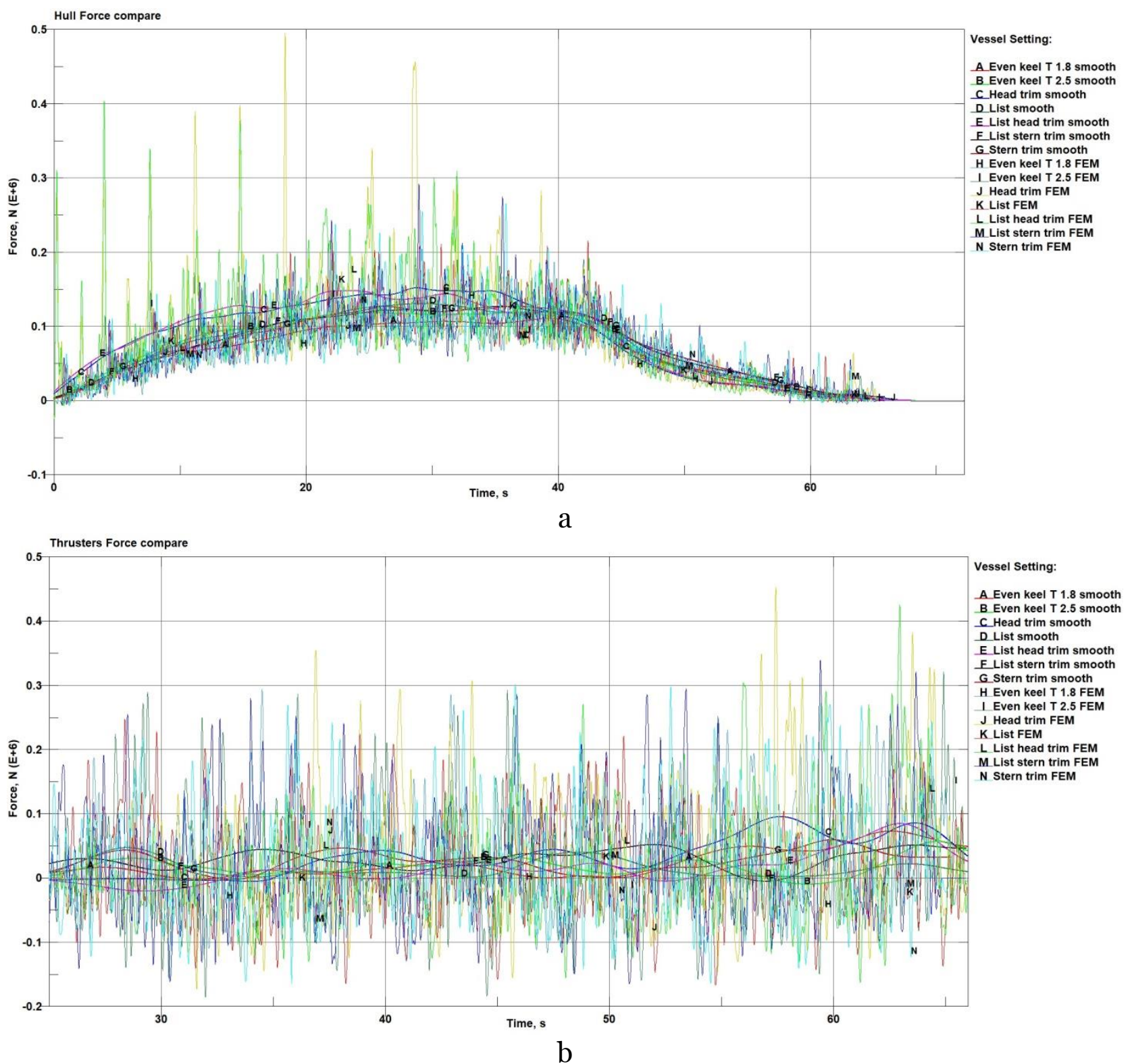

Vessel Setting:

A Even keel T 1.8 smooth B Even keel T 2.5 smooth C. Head trim smooth List head trim smooth EList stern trim smooth G Stern trim smooth Even keel T $2.8 \mathrm{FEM}$ $\mathrm{J}$ Head trim FEM $\mathrm{K}$ List FEM L List head trim FEM $\mathrm{M}$ List stern trim FEM 


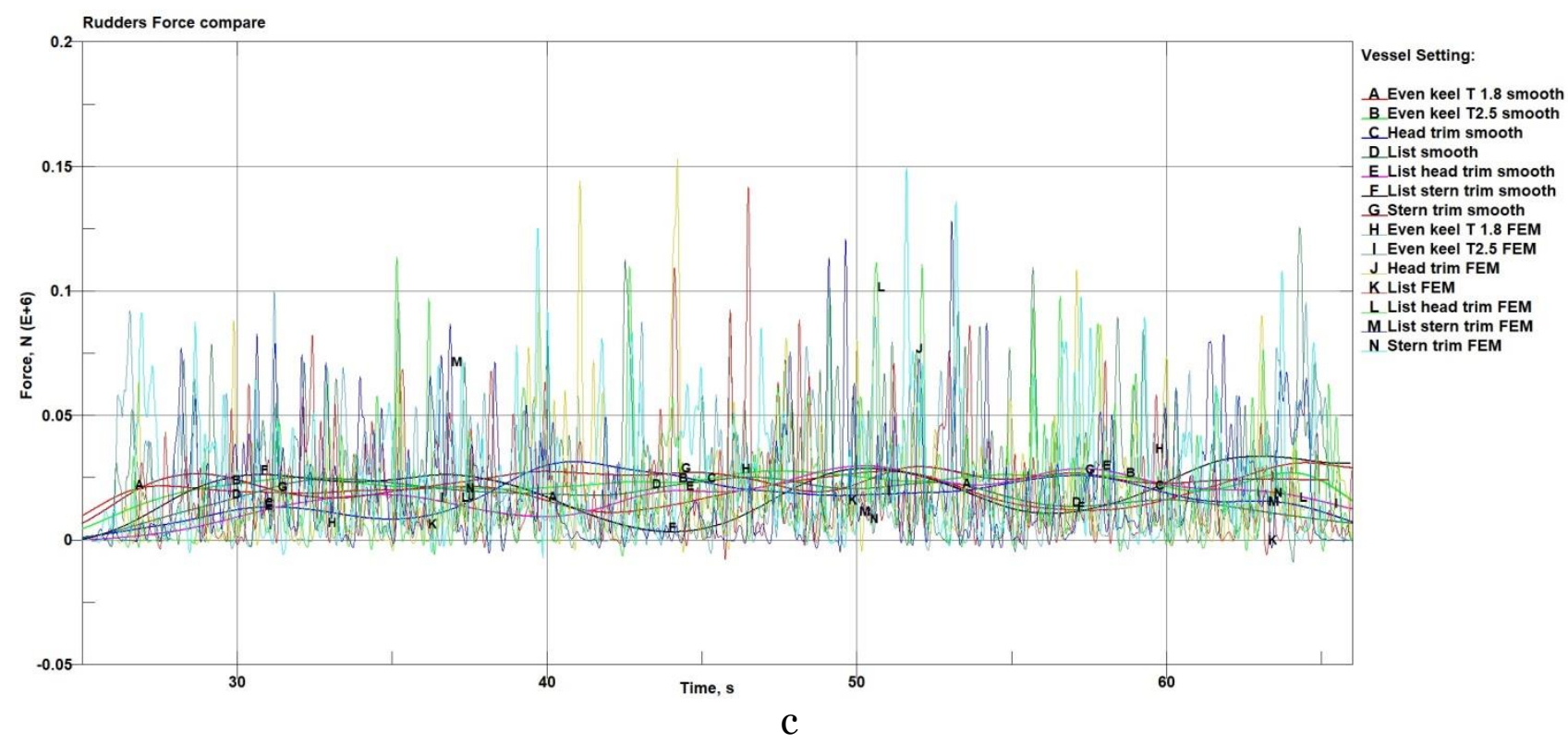

Fig. 7. Comparison of components of ice resistance of the icebreaker in ice cakes at different options of its sitting

( $\mathrm{a}$ - the ice resistance of the hull; $\mathrm{b}$ - the ice resistance of propellers; $\mathrm{c}$ - the ice resistance of rudders)

At the same time it is necessary to pay attention to sign-variable character of ice resistance of propellers (Fig. 7b). The considerable stochasticity of simultaneous interaction with the ice environment of four thrusters gives rather low level (a little more than 5\%) of this ice resistance component in overall balance of longitudinal ice loads on the vessel.

As a continuous ice cover on this stage of research is considered, it is possible to state unambiguously only about influence of a list on the ice resistance of the icebreaker (Fig. 8).

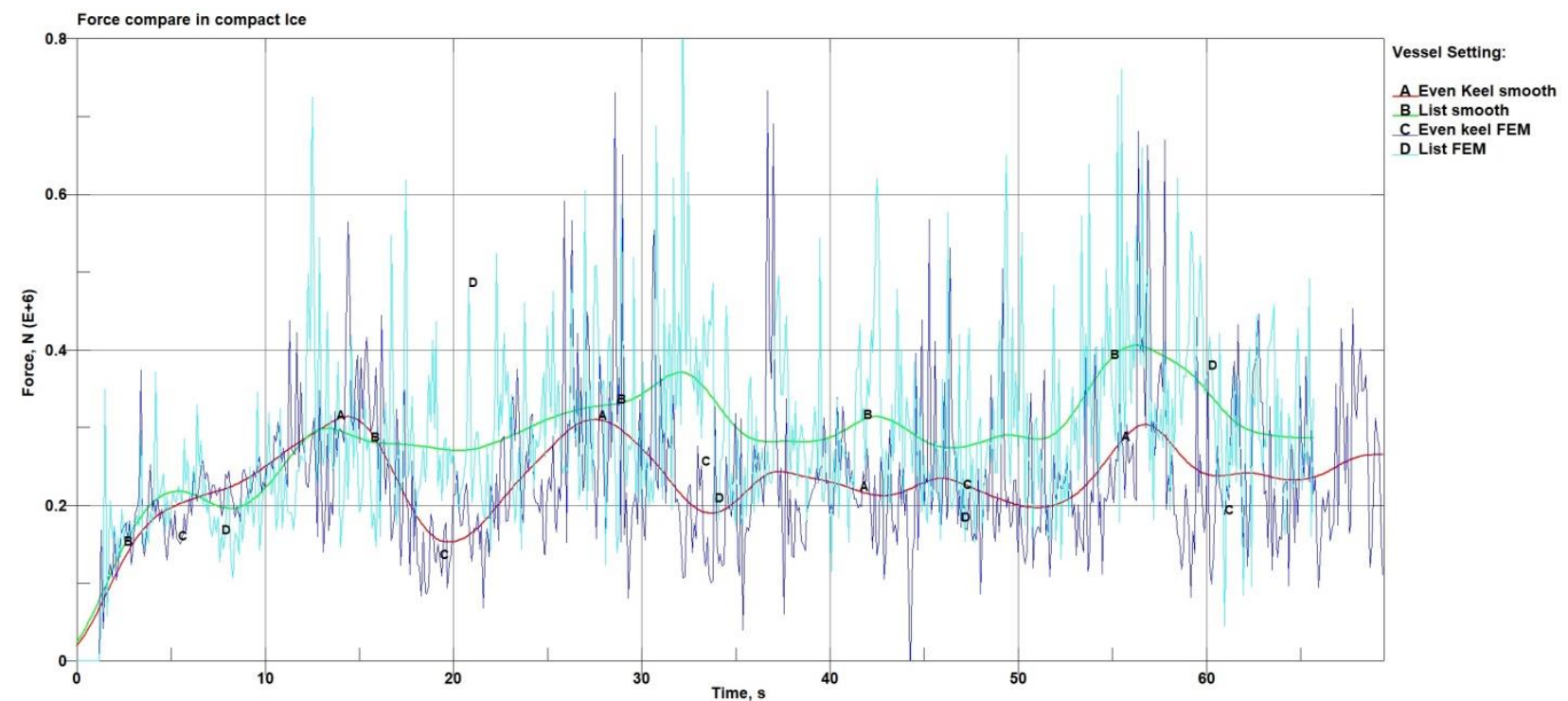

Fig. 8. Comparison of ice resistance of the icebreaker in compact ices at different options of its sitting

(A - sitting on «even keel» at the draft of 2,5 m, smoothed values; B - a list of 5 degrees, smoothed values; C-D - according to curve A-B results of CAE modeling)

At the same time within the safe range of this parameter we can note the notable gain of total ice resistance of the vessel (25-30\%) in comparison with its sitting on «even keel» (Fig. 8, comparison of curves $\mathrm{A}$ and $\mathrm{B}$ ). 


\section{Conclusion}

1. There is a sufficient number of partial problems of safety in the field of ice navigation. Generally they are caused by requirements of optimization of vessels maneuvering (including joint) in different ice conditions during the short-term period of time (ranging from several minutes to several tens minutes). Expert experience in area has showed that in such cases the forecast of safe conditions from positions of averaging of influence of set of ice arguments (as propose traditional solutions) will give a low forecast success rate. Therefore at impossibility of implementation of full-scale ice tests of vessels the model experiment (including virtual (CAE experiment)) remains a reliable alternative of definition of their special ice performances.

2. Distribution of ices and their degree of fragmentation in «model» ice channels indicate weak correlation of a ship sitting and qualitative condition of the ice channel, and functional communication of icebreaker sitting with the level of total ice resistance is not significant. At the same time in each option of an icebreaker sitting safe operating conditions of transport ships of not Arctic ice categories - small ice cakes and brash ice are provided.

3. For compact ices CAE experiments predict only influence of a list on the ice resistance of the icebreaker. At the same time deterioration in its route stability generates tortuosity of the ice channel, reducing the level of ice safety of the carried-out transport ships of not Arctic ice categories.

\section{References}

1. Akihisa Konno, Akihiro Nakane, Satoshi Kanamori. Validation of numerical estimation of brash ice channel resistance with model test. Proceedings of the 22 International Conference on Port and Ocean Engineering under Arctic Conditions. June 9-13, 2013, Espoo, Finland. - Access mode: http://www.poac.com/Papers/2013/pdf/POAC13 143.pdf

2. Anthony F. Molland., Stephen R. Turnock., Dominic A. Hudson. Ship Resistance and Propulsion: practical estimation of ship propulsive power. - New York: Cambridge University Press. 2011. - 537 p. http://dl.kashti.ir/ENBOOKS/NEW/Ship\%2oresistance\%20and\%20propulsion\%20 \%2 oF.Molland\%20(2011).pdf

3. Junji Sawamura, Ryouhei Kikuzawa, Takashi Tachibana, Masaya Kunigita. Numerical investigation of the ice Force Distribution around the Ship Hull in level Ice. Proceedings of the 21 International Conference on Port and Ocean Engineering under Arctic Conditions. July 10-14, 2011, Montreal, Canada. - Access mode: http://www.poac.com/PapersOnline.html

4. V. A. Lobanov, V. S. Pershina. Visualization of CAE-solutions of partial problems of ice navigation. Vessels passing. Scientific Visualization, 2018, volume 10, number 1, pages 89 - 98, DOI: 10.26583/sv.10.1.07 - Access mode: http://sv-journal.org/20181/07/?lang=en

5. E.M. Appolonov, K.E. Sazonov, A.A. Dobrodeev, N.Yu. Klementieva, M.A. Kudrin, E.A. Maslich, V.O. Petinov, V.M. Shaposhnikov. Studies to develop technologies for making a wider channel in ice. Proceedings of the 22 International Conference on Port and Ocean Engineering under Arctic Conditions. June 9-13, 2013, Espoo, Finland. - Access mode: http://www.poac.com/Papers/2013/pdf/POAC13 041.pdf

6. Ionov B.P., Gramuzov E.M. Ledovaya xodkost` sudov. 2 izdanie, ispravlennoe. - SPb.: Sudostroenie, 2014. - 504 s., il. [in Russian]

7. Kashtelyan V.I., Poznyak I.I., Ry`vlin A.Ya. Soprotivlenie l`da dvizheniyu sudna. - L.: Sudostroenie, 1968. - 238 s. [in Russian]

8. Tronin V.A. Povy`shenie bezopasnosti i e`ffektivnosti ledovogo plavaniya sudov na vnutrennix vodny `x putyax: dissertaciya na soiskanie uchyonoj stepeni doktora texnicheskix nauk: special `nost` 05.22.16 - Sudovozhdenie / Gor` kij, 1990. - 414 s. [in Russian] 
9. E`kspluatacionno-texnicheskie ispy`taniya transportny`x $\mathrm{i}$ ledokol`ny`x sudov v ledovy`x usloviyax s razrabotkoj predlozhenij, obespechivayushhix ix kruglogodovuyu e `kspluataciyu. Otchyot o nauchno-issledovatel`skoj rabote po teme №XV-3.2/794147. Nauchny`e ruk. - Tronin V.A., Bogdanov B.V. - Gor `kij.: GIIVT, 1981. - 262 s. [in Russian]

10. Lobanov V.A. Chislennaya ocenka ledovy`x kachestv sudna. Upravlyaemost`. Vestnik nauchno-texnicheskogo razvitiya, №8, 2012. E`lektronny`j zhurnal, № gos. reg. 0421200120, ISSN 2070-6847. http://www.vntr.ru/ftpgetfile.php?id=619 [in Russian]

11. Lobanov V.A. Razrabotka s primeneniem CAE-sistem normativny`x dokumentov po bezopasnosti ledovogo plavaniya sudna //Internet-zhurnal «Naukovedenie». 2013 №4 (17) [E`lektronny`j resurs]. - M. 2013. - s. 1-14. - Access mode: http://naukovedenie.ru/PDF/71tvn413.pdf, svobodny`j - Zagl. s e`krana. [in Russian]

12. Livermore Software Technology Corporation. LS-DYNA. - Access mode: https://www.lstc.com/products/ls-dyna 